\title{
Expansion of myeloid-derived suppressor cells with arginase activity lasts longer in aged than in young mice after CpG-ODN plus IFA treatment
}

\author{
María F. Harman ${ }^{1}$, Romina P. Ranocchia ${ }^{1}$, Carolina V. Gorlino, María F. Sánchez \\ Vallecillo ${ }^{1}$, Sofía D. Castell ${ }^{1}$, María I. Crespo ${ }^{1}$, Belkys A. Maletto ${ }^{1}$, Gabriel Morón ${ }^{1}$, \\ María C. Pistoresi-Palencia ${ }^{1}$ \\ ${ }^{1}$ Centro de Investigación en Bioquímica Clínica e Inmunología, Consejo Nacional de Investigaciones Científicas y Técnicas, \\ Facultad de Ciencias Químicas, Universidad Nacional de Córdoba, Córdoba, Argentina
}

Correspondence to:

María C. Pistoresi-Palencia, e-mail: cpistore@fcq.unc.edu.ar

María Florencia Harman, e-mail: mharman@fcq.unc.edu.ar

Keywords: aging, myeloid-derived suppressor cells, arginase, CpG-ODN, immunomodulation

Received: February 18, $2015 \quad$ Accepted: March 15, $2015 \quad$ Published: April 13, 2015

\section{ABSTRACT}

As we age, the homeostatic function of many systems in the body, such as the immune function declines, which in turn contributes to augment susceptibility to disease. Here we describe that challenging aged mice with synthetic oligodeoxynucleotides containing unmethylated cytosine guanine motifs (CpG-ODN) emulsified in incomplete Freund's adjuvant (IFA), (CpG-ODN+IFA) an inflammatory stimulus, led to the

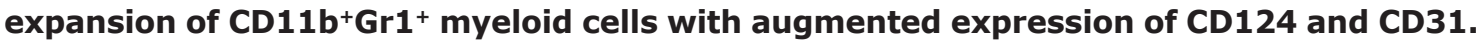
These myeloid cells lasted longer in the spleen of aged mice than in their younger counterparts after CpG-ODN+IFA treatment and were capable of suppressing $T$ cell proliferative response by arginase induction. Myeloid cells from aged CpG-ODN+IFAtreated mice presented increased arginase-1 expression and enzyme activity. In addition, we found a different requirement of cytokines for arginase induction according to mice age. In myeloid cells from young treated mice, arginase-1 expression and activity is induced by the presence of each IL-4 or IL-6 in their extracellular medium, unlike myeloid cells from aged treated mice which need the presence of both IL- 4 and IL-6 together for arginase induction and suppressor function.

\section{INTRODUCTION}

Myeloid-derived suppressor cells (MDSCs) are a heterogeneous population of cells that consist of myeloid progenitors and immature myeloid cells [1]. Immature myeloid cells with the same phenotype as MDSCs are continually generated in the bone marrow of healthy individuals and differentiate into mature myeloid cells: granulocytes, macrophages or dendritic cells [1-2]. However, under inflammatory conditions, MDSC levels are elevated in peripheral secondary lymph organs in both human [3] and murine [4-6] hosts. MDSCs regulate both innate and adaptative immunity [7], and are responsible for suppressing T-cell responses [1]. MDSCs are identified in mice by the coexpression of the myeloid-cell lineage differentiation antigen CD11b and Gr1 [1]. A number of cytokines and transcription factors were shown to modulate the expansion and activation of MDSCs [1,8]. MDSC exerts its suppressive activity upregulating the expression of factors such as arginase-1 and iNOS, as well as increasing the production of nitric oxide and reactive oxygen species [1].

Aging impacts the homeostatic function of many systems in the body, including the immune system, which reduces the capacity to mount a robust immune response [9-11]. As a result, elderly individuals experience a higher incidence of various diseases, such as autoimmune disorders, infections and cancer.

We have previously demonstrated that $\mathrm{CpG}-\mathrm{ODN}$ used as an adjuvant was able to induce a specific immune response in aged mice comparable to that in young mice [12-14]. We have also demonstrated that systemic administration of $\mathrm{CpG}-\mathrm{ODN}$ emulsified in incomplete Freund's adjuvant (CpG-ODN+IFA) induced transitory expansion of splenic MDSCs with $\mathrm{CD} 11 \mathrm{~b}^{+} \mathrm{Gr} 1^{+}$phenotype 
in young mice, which caused suppression of T-cell proliferation mediated by arginase activity [15]. Thus, CpG-ODN, besides being a powerful immunostimulatory compound, is capable of inducing MDSCs as a counterregulatory response in young mice.

Based on all these considerations, we aimed to investigate the effects of aging on the expansion and suppressor function of myeloid cells in CpG-ODN+IFAtreated mice.

The data presented in this work show that CpGODN+IFA is capable of inducing the expansion of myeloid cells in aged mice, which remain elevated for a longer time than in their younger counterparts. Myeloid cells from aged treated mice suppress the $\mathrm{T}$ cell proliferative response by arginase induction. Here we found a different requirement of cytokines for arginase induction according to mice age. In myeloid cells from young treated mice, arginase- 1 expression and activity is induced by the presence of each IL-4 or IL-6 in their extracellular medium, unlike myeloid cells from aged treated mice which need the presence of both IL-4 and IL-6 together for arginase induction and suppressor function. Further investigation of the functional consequences of elevated MDSCs for more time facing an inflammatory stimulus will provide valuable insight into the progression of agerelated pathologies.

\section{RESULTS}

\section{$\mathrm{CD}_{11 \mathrm{~b}^{+}} \mathrm{Gr}^{+}$myeloid cells accumulate in the spleen of CpG-ODN+IFA-treated aged mice}

It is well known that human and murine hematopoietic stem cells exhibit cell autonomous changes during aging, showing attenuated lymphoid lineage output, while myeloid lineage potential is maintained or even increased $[10-11,16]$. For this reason, we first

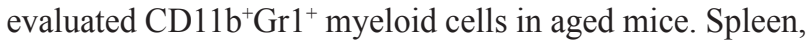
blood and bone marrow compartments of aged mice contained higher numbers of $\mathrm{CD} 11 \mathrm{~b}^{+} \mathrm{Gr} 1^{+}$cells compared to young animals (Figure 1A and Supplementary Figure 1A). Similar results have been recently reported by other authors [17-18] although we further observed a lower percentage of apoptotic $\mathrm{CD} 11 \mathrm{~b}^{+} \mathrm{Gr} 1^{+}$cells from aged mice compared to young animals indicating that they have a prolonged life span (Figure 1B), which may be another reason for their increased number in aged mice.

We have recently reported that the numbers of

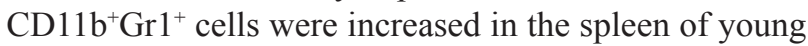
$\mathrm{BALB} / \mathrm{c}$ mice after a single administration of $\mathrm{CpG}$ ODN+IFA [15]. With this in mind, we investigated

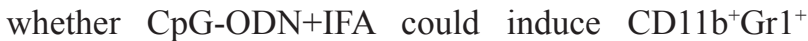
cells expansion in aged mice. As shown in Figure $1 \mathrm{C}$ and 1D, 10 days after CpG-ODN+IFA-treatment, the percentage and absolute number of $\mathrm{CD} 11 \mathrm{~b}^{+} \mathrm{Gr} 1^{+}$cells were significantly augmented in spleen of aged mice compared to saline solution-treated mice. Although the expansion of myeloid cells after treatment reached similar levels as in their younger counterparts their induction was lower because of their basal augmented number (Supplementary Figure 1B).

In order to evaluate the expression of myeloid lineage differentiation and maturation markers in myeloid cells that accumulated in the spleen of aged mice after CpG-ODN+IFA treatment, flow cytometry analysis was performed. We observed upregulated expression of CD124 (IL-4R $\alpha$ ) and CD31; however, no significant differences were found in the expression of PD-L1, PD-L2, MHC-II and CD86 in these cells (Figure 1E).

Recent reports indicated that MDSCs can be divided into two distinct subsets based on their expression of two Gr1 epitopes, Ly6G and Ly6C: granulocytic MDSCs with CD11 ${ }^{+}$Ly6G $^{+}$Ly6C $^{\text {low }}$ phenotype and monocytic MDSCs with $\mathrm{CD}_{11 b^{+} \text {Ly6G }}{ }^{-}$Ly6C ${ }^{\text {high }}$ phenotype $[1,6,19]$. After CpG-ODN+IFA treatment, both monocytic and granulocytic subpopulations were increased in spleen of aged and young mice (Figure 1F); however, the granulocytic subset was the predominant population of myeloid cells that expanded (Figure 1F). As spleens of aged saline solution-treated mice harbor higher numbers of myeloid cells the increase of both subsets after treatment was lower in these animals than in their younger counterparts.

Collectively our data indicate that secondary lymphoid organs of aged mice harbor an elevated number of $\mathrm{CD}_{1} \mathrm{~b}^{+} \mathrm{Gr}^{+}$myeloid cells which are less sensitive to spontaneous apoptosis than their younger counterparts. Besides, after CpG-ODN+IFA-treatment of aged mice, this myeloid cell population expanded and presented phenotype characteristics of MDSCs.

\section{Myeloid cells from aged CpG-ODN+IFA-treated mice suppress $\mathbf{T}$ cell proliferative response}

MDSCs which accumulate during cancer, inflammation and infection have a remarkable ability to suppress $\mathrm{T}$ cell responses, and this function is their defining characteristic [1]. First, we performed an in vitro proliferative assay of splenocytes to evaluate the effect of the expansion of myeloid cells by CpG-ODN+IFA treatment. We observed a reduction in the proliferative response to ConA of splenocytes from aged mice after CpG-ODN+IFA treatment, similar to that occurring in splenocytes from young treated mice (Figure 2A). To examine if the lower proliferative response was due to the expansion of the myeloid cell population with suppressor function, we evaluated the suppressor activity of myeloid cells isolated from spleen of aged CpG-ODN+IFA-treated mice. T-cells from young syngeneic mice stimulated with anti-CD3 plus anti-CD28 were used as responders. T cell proliferative response was lower when they were cultured with myeloid cells from aged CpG-ODN+IFA-treated mice, compared to cultures with myeloid cells from saline 

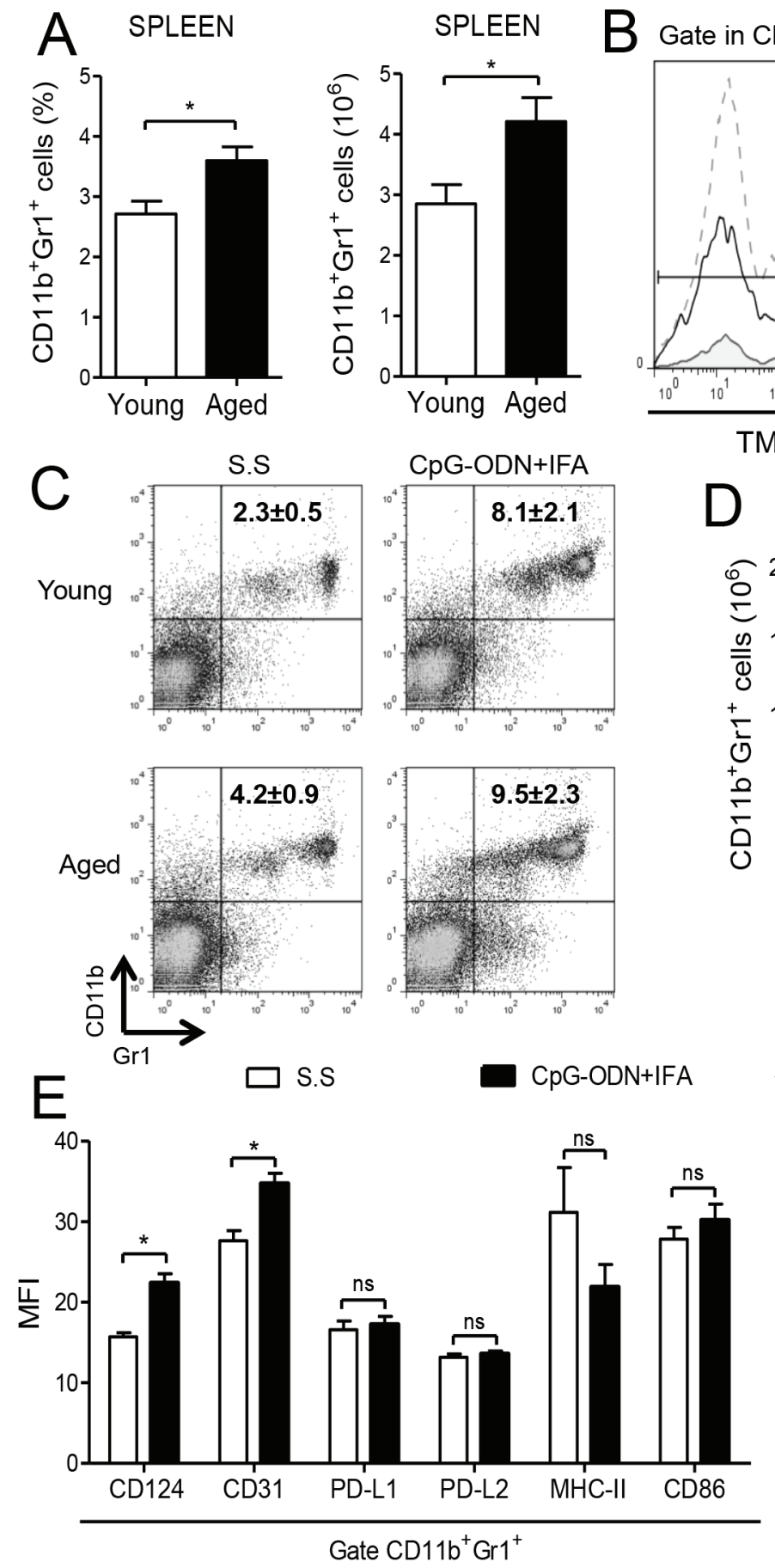

CpG-ODN+IFA
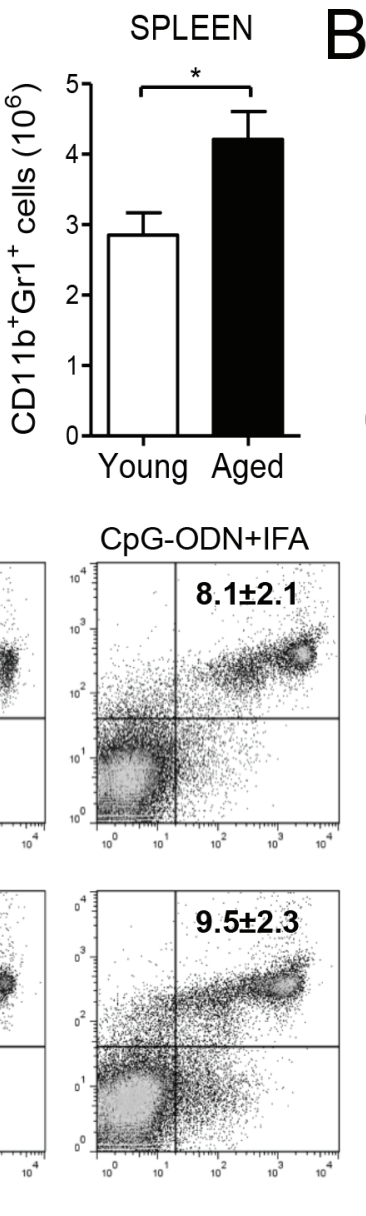

CpG-ODN+IFA
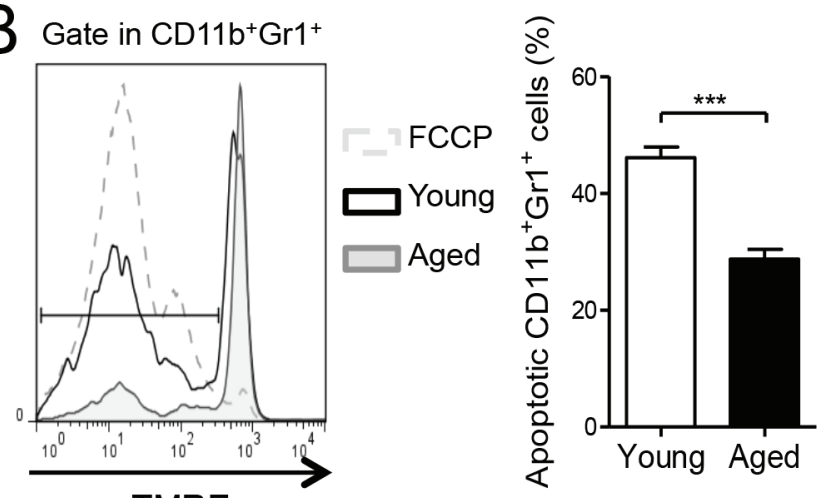

TMRE

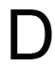

S.S

CpG-ODN+IFA

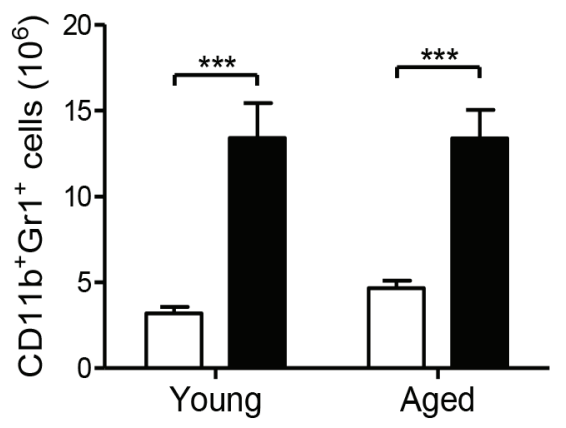

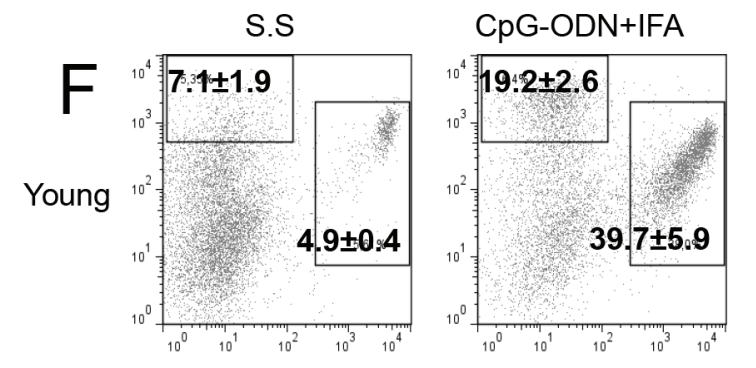
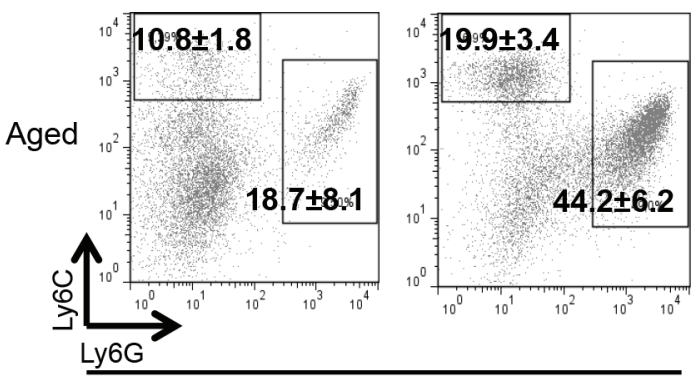

Gate in CD11b+

Figure 1: Myeloid cells accumulate in spleen of CpG-ODN+IFA-treated aged mice. (A-B) Splenocytes from young and aged mice were stained with anti-CD11b and anti-Gr1 antibodies and analyzed by flow cytometry. (A) Percentage and absolute number of $\mathrm{CD}_{11 \mathrm{~b}^{+} \mathrm{Gr}^{+}}$cells are presented. (B) Percentage of apoptotic myeloid cells determined by TMRE staining (TMRE ${ }^{\text {low }}$ cells) on $\mathrm{CD} 11 \mathrm{~b}^{+} \mathrm{Gr} 1^{+}$gated splenocytes from young and aged mice, after $18 \mathrm{~h}$ of culture without stimuli. Cells incubated with FCCP were used as positive control. (C-E) Splenocytes were collected from mice ten days after CpG-ODN+IFA or Saline solution (S.S) treatment and analyzed by flow cytometry. (C) Representative dot plots with percentages $\left(* * *<0.001\right.$ young CpG-ODN+IFA vs S.S, ${ }^{* *} p<0.01$ aged CpG-ODN+IFA vs S.S; mean \pm SEM) and (D) absolute number of CD11 b $\mathrm{Grl}^{+}$cells in spleen from young and aged mice are presented.

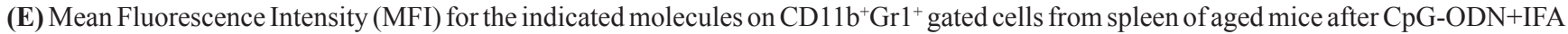
or S.S treatment. (F) Representative dot plots and percentages of CD11b ${ }^{+} \mathrm{Ly} 6 \mathrm{G}^{-} \mathrm{Ly} 6 \mathrm{C}^{\text {high }}$ and $\mathrm{CD} 11 \mathrm{~b}^{+} \mathrm{Ly} 6 \mathrm{G}^{+} \mathrm{Ly} 6 \mathrm{C}^{\text {low }}$ cells are shown as mean \pm SEM; granulocytic population: $* * p<0.01 \mathrm{CpG}-\mathrm{ODN}+\mathrm{IFA}$ vs S.S (young and aged), monocytic population: $* * p<0.01 \mathrm{CpG}-\mathrm{ODN}+\mathrm{IFA}$ vs S.S (young and aged). Data are from (A, C-D) four and (B, E-F) three independent experiments; mean \pm SEM ( $n=4$ mice/group) ${ }^{*} p<0.05 ; * * p<0.01 ; * * * p<0.001$. 


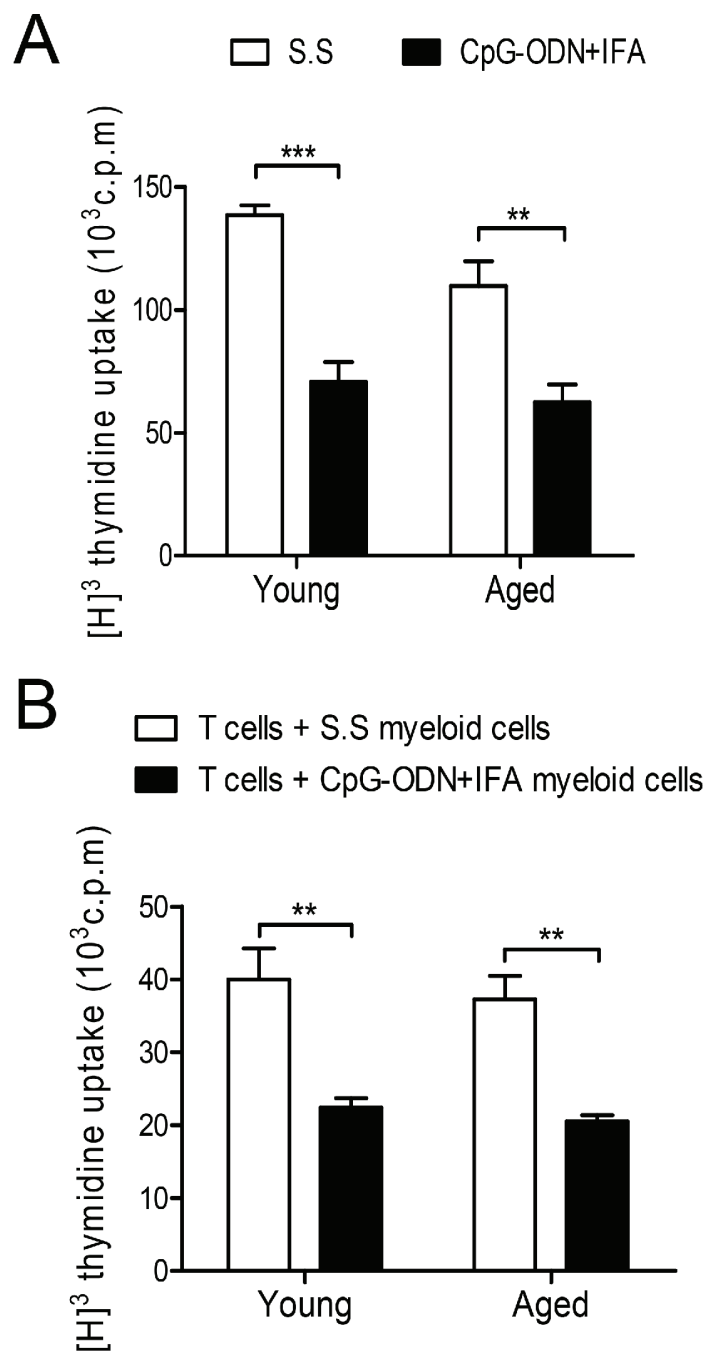

Figure 2: Myeloid cells from aged CpG-ODN+IFA-treated mice suppress T cell proliferation. Spleens were collected from young and aged mice after ten days of CpG-ODN+IFA-treatment. (A) Splenocytes were stimulated with ConA or RPMI (unstimulated) and cultured for $72 \mathrm{~h}$. (B) Naïve T cells isolated from young mice were stimulated with anti-CD3 plus anti-CD28 and co-cultured, at a 1:1 ratio, with myeloid cells purified from young or aged S.S or CpG-ODN+IFA-treated mice for $48 \mathrm{~h}$. (A-B) T cell proliferation was measured by $\left[{ }^{3} \mathrm{H}\right]$-Thymidine incorporation after $18 \mathrm{~h}$ pulse. Values are represented as c.p.m of stimulated minus unstimulated. (A-B) Data are representative of three independent experiments; mean $\pm \operatorname{SEM}(n=4$ mice/group $) * * p<0.01 ; * * * p<0.001$.

solution-treated aged mice (Figure 2B). Interestingly the reduction of $\mathrm{T}$ cell proliferation was similar when the co-cultures were performed with myeloid cells isolated from young or aged treated mice.

The results indicate that myeloid cells from aged CpG-ODN+IFA-treated mice are capable of suppressing T-cell proliferative response as effectively as myeloid cells from young treated mice.

\section{Myeloid cells from aged CpG-ODN+IFA-treated mice suppress $\mathbf{T}$ cell proliferation by arginase}

We have previously shown that the $\mathrm{T}$ cell suppressor ability of myeloid cells from young mice after CpGODN+IFA treatment was linked to a mechanism based on L-arginine depletion by arginase activity [15]. We therefore investigated whether arginase activity was induced in splenocytes of aged mice after CpG-ODN+IFA treatment. As shown in Figure 3A, splenocytes from aged treated mice exhibited greater arginase activity than splenocytes from their saline solution-treated counterparts. Intracellular staining showed increased arginase-1 protein expression in $\mathrm{CD} 11 \mathrm{~b}^{+} \mathrm{Gr} 1^{+}$cells from aged and young mice after CpG-ODN+IFA treatment (Figure 3B). To confirm these results, myeloid cells from aged CpG-ODN+IFAtreated mice were isolated and cultured with stimulated $\mathrm{T}$ cells from young mice. Arginase activity increased in these myeloid cells and, as expected, no activity was detected in the negative fraction (Figure 3C). Similar results were obtained in cultures of myeloid cells from young CpG-ODN+IFA-treated mice (Figure 3C). Interestingly, myeloid cells from aged saline solution-treated mice 

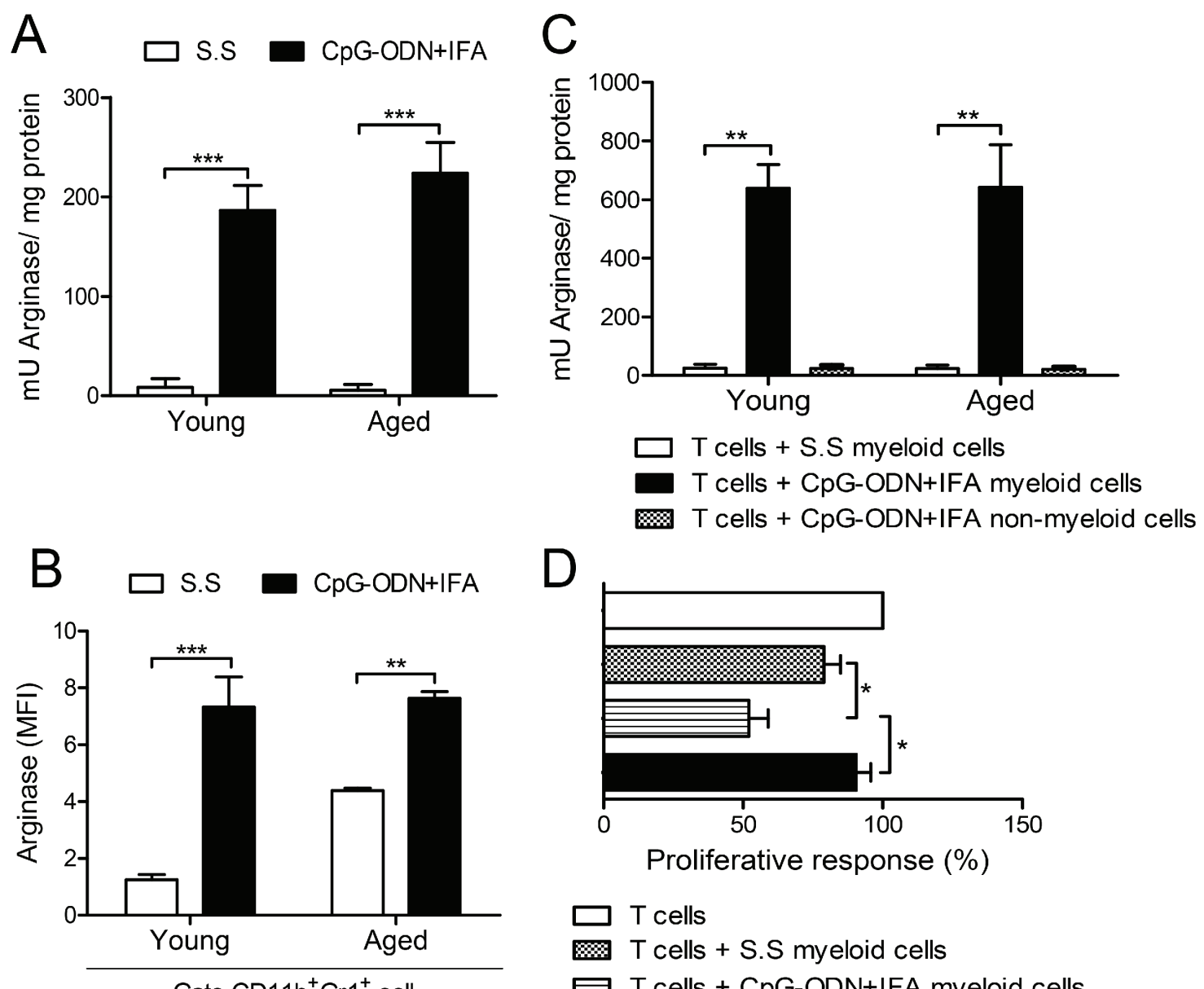

$\mathrm{D}$
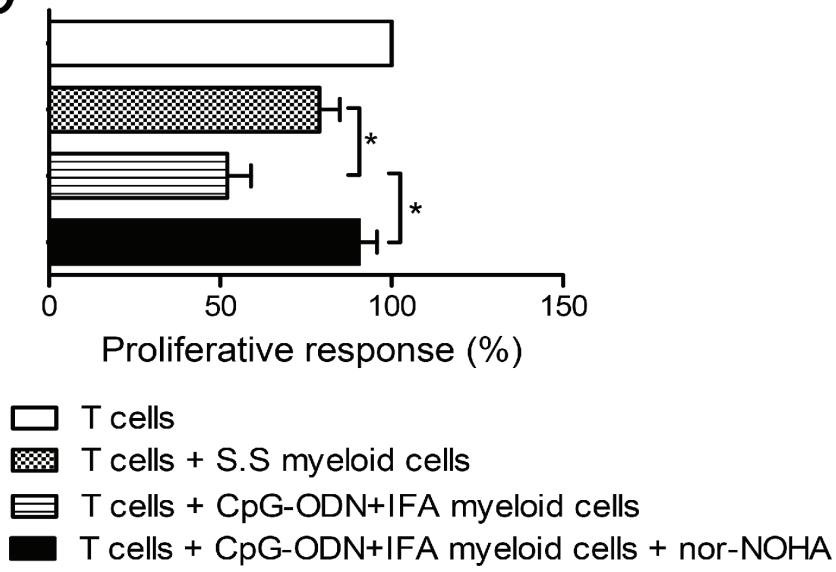

Figure 3: Myeloid cells from aged CpG-ODN+IFA-treated mice suppress $\mathbf{T}$ cell proliferation by arginase. Spleens were obtained from mice after ten days of CpG-ODN+IFA or S.S-treatment. (A) Splenocytes from young and aged mice were stimulated with ConA or RPMI for $72 \mathrm{~h}$, lysed and prepared for arginase activity analysis. (B) Mean Fluorescence Intensity (MFI) for arginase-1 on CD11 b $\mathrm{Gr}^{+}$ gated splenocytes from young and aged mice after $48 \mathrm{~h}$ culture with ConA or RPMI. (C) Isolated myeloid cells from young and aged S.S or CpG-ODN+IFA-treated mice were co-cultured with naïve T-cells isolated from young mice stimulated with anti-CD3 plus anti-CD28 and then prepared for arginase activity analysis. $\mathrm{CD}_{11} \mathrm{~b}^{-}$spleen cells from CpG-ODN+IFA-treated-mice (non-myeloid cells) were used as control. (A and C) Results are expressed as mU of enzyme activity per mg of protein lysate (Stimulated minus unstimulated). (D) Isolated naïve T-cells from young mice were stimulated with anti-CD3 plus anti-CD28 and co-cultured with purified myeloid cells, from aged S.S or CpGODN+IFA-treated mice, in the presence or absence of nor-NOHA, T-cell proliferation was measured by [ $\left.{ }^{3} \mathrm{H}\right]$-Thymidine incorporation after 18 $\mathrm{h}$ pulse, values are represented as fold increase related to stimulated T-cell alone proliferative response (100\%). Results are representative of (A and C) three and (B and D) two experiments performed (mean $\pm \operatorname{SEM} n=4$ mice/group) $* p<0.05 ; * * p<0.01 ; * * * p<0.001$.

showed higher arginase-1 expression compared to their younger counterparts (Figure 3B) although no arginase activity was observed in these cells (Figure 3C).

Our results suggest that there is a close correlation between arginase activity in myeloid cells from aged CpGODN+IFA-treated mice and their capacity to regulate T-cell proliferation. To examine this issue, the arginase inhibitor, nor-NOHA, was added to the co-cultures of stimulated T-cells and myeloid cells isolated from aged CpG-ODN+IFA-treated mice. As shown in Figure 3D, $\mathrm{T}$ cell proliferative response was restored by nor-NOHA, showing similar proliferation levels to that of T-cells cultured with myeloid cells from saline solution-treated mice or T cells alone.
These findings demonstrate that the induction of arginase is one of the major mechanisms involved in the suppressive capacity of myeloid cells from aged CpGODN+IFA-treated mice.

\section{Myeloid-derived suppressor cell expansion lasts longer in aged than in young mice after CpG-ODN+IFA treatment}

We next asked how long it takes for myeloid cells to return to basal levels in aged mice after CpG-ODN+IFA treatment. We studied these cells at different time points after treatment. As mentioned before, 10 days after treatment there was a marked expansion of myeloid cell 
population in young mice and as shown in Figure 4A, they returned to basal levels on day 25 . In contrast, the population of myeloid cells that expanded on day 10 in aged mice remained elevated at least 40 days after $\mathrm{CpG}$ ODN+IFA-treatment (Figure 4A).

We next isolated myeloid cells from mice 40 days after CpG-ODN+IFA-treatment and cultured them with stimulated $\mathrm{T}$ cells in order to evaluate the preservation of their immunosuppressive capacity. At this time point, myeloid cells obtained from aged mice conserved high arginase activity whereas myeloid cells from young animals presented the same levels as their saline solution counterparts (Figure 4B). A similar result was observed with total splenocytes (data not shown). Moreover, T cell proliferative response was reduced when myeloid cells isolated from aged mice 40 days after $\mathrm{CpG}-\mathrm{ODN}+\mathrm{IFA}$-treatment were added to the co-cultures, indicating that these cells were still suppressive (Figure 4C). In contrast, myeloid cells purified from young mice after 40 days of treatment did not suppress $\mathrm{T}$ cell proliferation (Figure 4C).

Finally, myeloid cell levels in spleen of aged mice 80 days after CpG-ODN+IFA-treatment were the same as those observed in their saline solution counterparts (Figure 4D), indicating that the expanded population had already returned to its basal levels by this time.
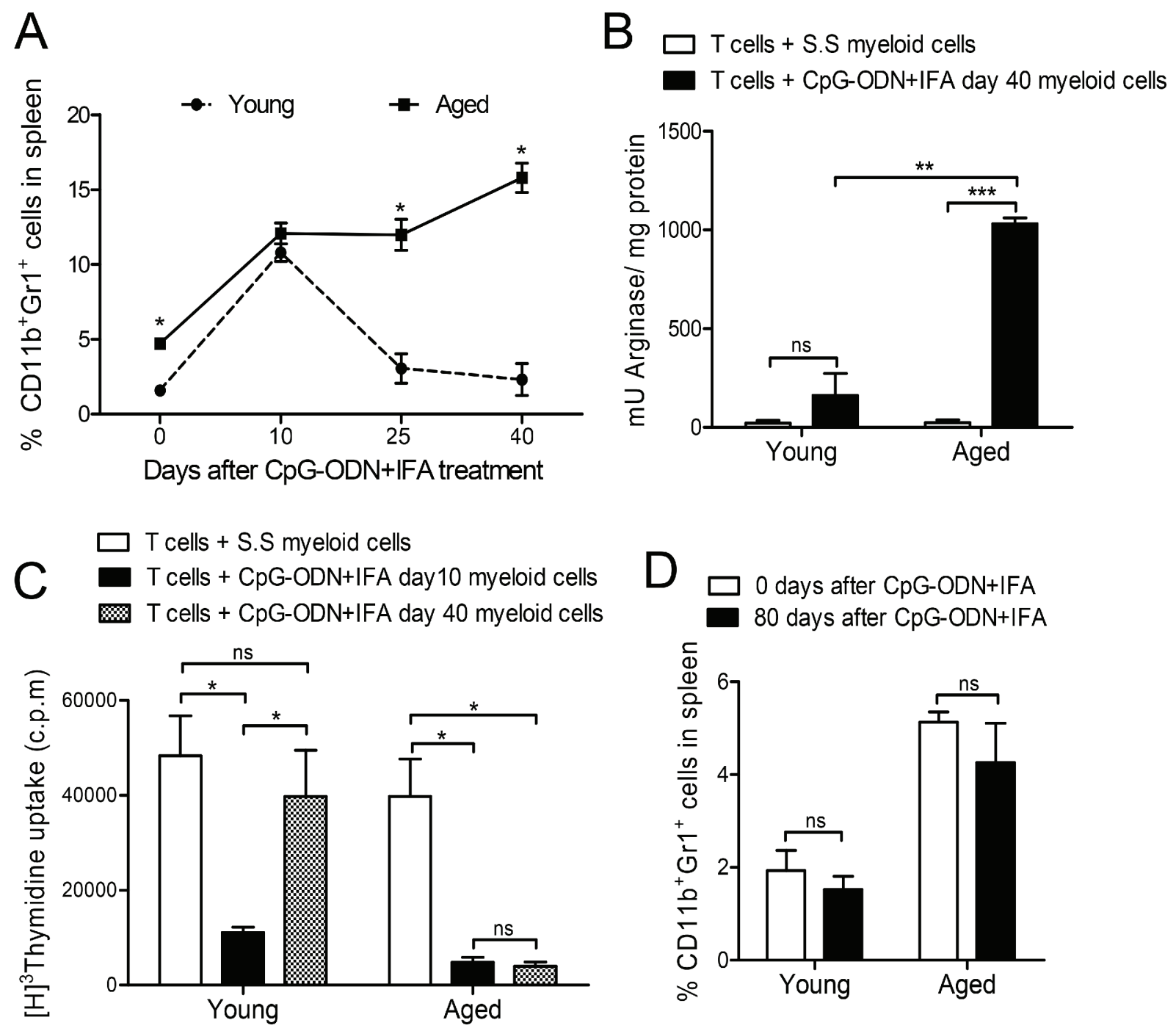

Figure 4: Myeloid suppressor cell expansion lasts longer in aged than in young mice after CpG-ODN+IFA treatment. (A) Splenocytes from young and aged mice were obtained 0, 10,25 and 40 days after treatment, stained with anti-CD11b and anti-Gr1 and analyzed by flow cytometry. (B) Myeloid cells were isolated from young and aged mice 40 days after S.S or CpG-ODN+IFA- treatment and cultured with naïve T cells from young mice stimulated with anti-CD3 and anti-CD28. Cells were prepared for arginase activity analysis. Results are expressed as $\mathrm{mU}$ of enzyme activity per $\mathrm{mg}$ of protein lysate. (C) Ten and 40 days after treatment, myeloid cells were isolated from spleen of young and aged treated mice and cultured with naïve T-cells from young mice stimulated with anti-CD3 and anti-CD28. T-cell proliferation was measured by [ $\left.{ }^{3} \mathrm{H}\right]-$ Thymidine incorporation after $18 \mathrm{~h}$ pulse, (values are represented as c.p.m of stimulated minus unstimulated). (D) Zero or 80 days after treatment, splenocytes were removed from mice, stained with anti-CD11b and anti-Gr1 and analyzed by flow cytometry. (A-D) Results are representative of three experiments performed (mean $\pm \mathrm{SEM} ; n=4$ mice/group). ${ }^{*} p<0.05 ; * * p<0.01 ; * * * p<0.001$ 


\section{Environmental IL-4 and IL-6 are involved in arginase induction in myeloid cells from CpG-ODN+IFA-treated mice}

Myeloid cells can be activated in response to local environmental signals. It has been established that IL-4 activating STAT6 may be a pathway that induces the expression of arginase-1 in MDSCs [1]. We found that IL-4 levels were augmented when stimulated T cells were co-cultured with myeloid cells from young or aged saline solution or CpG-ODN+IFA-treated mice (Figure 5A). In addition, although no significant differences were observed in IL-4 levels between the co-cultures of myeloid cells from saline solution and $\mathrm{CpG}-\mathrm{ODN}+\mathrm{IFA}$-treated mice (Figure 5A), we found that, after $240 \mathrm{~min}$ of co-culture, myeloid cells from young and aged CpG-ODN+IFAtreated mice presented increased STAT6 phosphorylation (Figure 5B). In line with these data, we found that CD124 (IL-4R $\alpha$ ) expression was upregulated in myeloid cells from
CpG-ODN+IFA-treated mice at both ages (Figure 1E and Supplementary Figure 2), which may be promoting IL-4 dependent activation of STAT6 in these cells.

In addition, recent studies showed that, among others, IL-6 was responsible for the phosphorylation of STAT3 and the expression of arginase-1 in myeloid cells [20-22]. We observed increased IL-6 levels in co-cultures of stimulated $\mathrm{T}$ cells with myeloid cells from young or aged $\mathrm{CpG}-\mathrm{ODN}+\mathrm{IFA}$-treated mice compared to their saline solution counterparts (Figure 5C). Consistent with these results, after $30 \mathrm{~min}$ of co-culture, myeloid cells from young and aged CpGODN+IFA-treated mice presented increased STAT3 phosphorylation (Figure 5D). These results correlated with the induced arginase activity and expression in myeloid cells from CpG-ODN+IFA-treated mice (Figure 3B and 3C).

To address the potential of IL- 6 and IL- 4 in the induction of arginase-1 expression in myeloid cells from
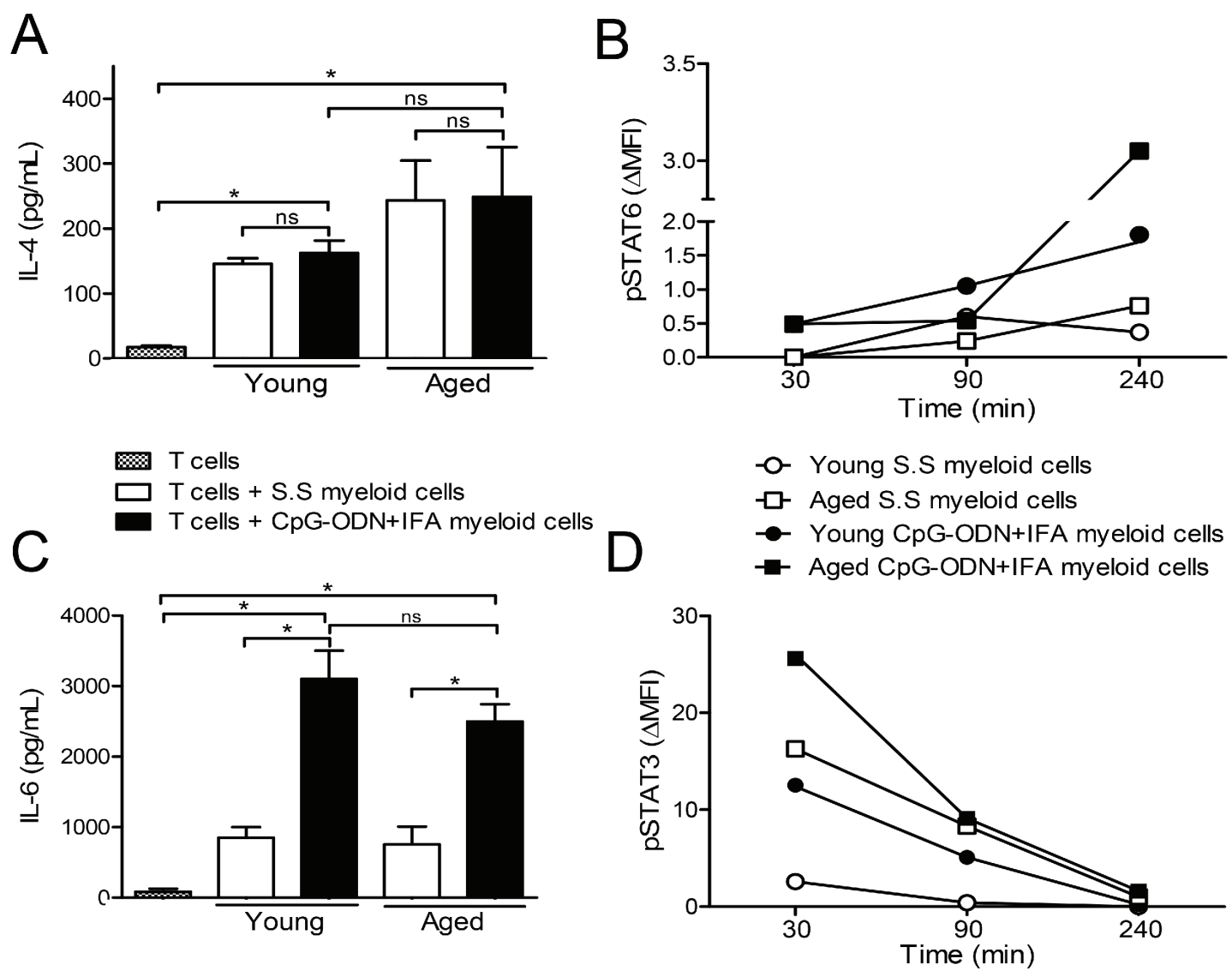

Figure 5: IL-4 and IL-6 in the extracellular medium of myeloid cells from CpG-ODN+IFA-treated mice. After 10 days of S.S or CpG-ODN+IFA-treatment, myeloid cells were isolated from the spleen of young and aged mice and cultured with naïve T cells isolated from young mice stimulated with anti-CD3 plus anti-CD28. (A and C) After $48 \mathrm{~h}$ of co-culture, supernatants were collected. (A) IL-4 and (C) IL-6 levels were measured by ELISA. (B and D) After 30, 90 and 240 min of co-culture, cells were collected, fixed, permeabilized, and stained with anti-CD11b, anti-Gr1, anti-STAT6(pY641) and anti-STAT3(pY705). (B) pSTAT6 and (D) pSTAT3 levels were analyzed on gated $\mathrm{CD} 1 \mathrm{~b}^{+} \mathrm{Grr}^{+}$myeloid cells. Results represent the expression (MFI) of pSTAT3 and pSTAT6 at 30, 90 and 240 min by subtracting that measured at zero time $(\triangle \mathrm{MFI})$. Data are shown from one representative experiment of $(\mathrm{A}-\mathrm{C})$ three, $(\mathrm{B}-\mathrm{D})$ two performed (mean $\pm \operatorname{SEM} n=4$ mice/group) ${ }^{*} p<0.05$. 
CpG-ODN+IFA-treated mice, we added neutralizing antibodies against IL-6, IL-4, or both together, to cocultures. When neutralizing antibody against IL-4 or IL-6 was separately added to the culture, arginase-1 expression in myeloid cells was substantially reduced at both ages (Figure 6A and Supplementary Figure 3). Unlike, when both neutralizing antibodies were present in the culture, the expression of arginase- 1 in the case of myeloid cells from young mice was even more reduced (Figure 6A). The neutralization of IL-4, IL-6 or both cytokines in the cultures of myeloid cells from aged treated mice reduced arginase-1 expression to lower levels than in their saline solution counterparts.

We next analyzed whether IL-4 and/or IL-6 neutralization also affected arginase activity in myeloid cells. The addition of neutralizing antibody against IL-4 or IL-6 alone substantially reduced arginase activity in cultures of myeloid cells from young treated mice, but only when both antibodies were added together was arginase activity completely inhibited (Figure 6B). In cultures of myeloid cells from aged mice, the addition of neutralizing antibody against IL-4 or IL-6 alone was sufficient to completely abrogate arginase activity (Figure 6B). As expected, the same occurred when both antibodies were added together.

As it has been well established that IL-4/STAT6 pathway is involved in arginase induction in myeloid cells, we focused our studies on the participation of the IL-6/STAT3 phosphorylation pathway. Interestingly, when neutralizing antibody against IL-6 was added to the cultures, we observed a reduction in STAT3 phosphorylation levels in myeloid cells from young and aged $\mathrm{CpG}-\mathrm{ODN}+\mathrm{IFA}$-treated mice (Figure 6C and Supplementary Figure 4). We also found that the levels of IL-10, another cytokine that may be responsible for STAT3 activation, were significantly reduced in cultures of $\mathrm{T}$ cells with myeloid cells from young or aged CpG-ODN+IFA-treated mice compared to their saline solution counterparts (data not shown). These results demonstrate that arginase activity and expression in myeloid cells from CpG-ODN+IFA-treated mice depend on IL-4 and IL-6 present in the T cell-myeloid cell extracellular microenvironment. Myeloid cells from aged CpG-ODN+IFA-treated mice require the presence of both cytokines for arginase induction, while IL-4 or IL-6 alone induces arginase in myeloid cells from young CpG-ODN+IFA-treated mice.

\section{DISCUSSION}

We have found, in agreement with other authors [17-18], that lymphoid tissues of aged mice harbor increased numbers of myeloid cells $\mathrm{CD} 11 \mathrm{~b}^{+} \mathrm{Gr} 1^{+}$. We have also demonstrated that these myeloid cells are more resistant to spontaneous apoptosis than their younger counterparts. Besides the well established evidence showing a myeloid-based output of the hematopoietic system with increasing age [11, 23-24], our results suggest the accumulation of myeloid cells in aged mice is likely to be related to an abnormally prolonged lifespan.

CpG-ODN were thought to be predominantly proinflammatory molecules. We and others have demonstrated the ability of CpG-ODN to act in aged mice as a strong adjuvant, resulting in the induction of a powerful antigen-specific immune response [12-14, 25]. However, current studies have shown the existence of CpG-ODN counter-regulatory mechanisms that prevent pathological immune-mediated damage [26-30]. Also, we have previously shown that CpG-ODN combined with IFN- $\gamma$ is able to stimulate arginase, an anti-inflammatory enzyme, in murine macrophages [31].

Besides this, in previous work we have shown that CpG-ODN+IFA induces in young mice the expansion of a myeloid cell population with high arginase-1 expression and enzymatic activity, responsible for reduced T-cell proliferation and CD3z chain downregulation in the TCR complex in T-cells [15].

Here we describe for the first time that aged mice present an expansion of a myeloid cell population with immunoregulatory functions, compatible with MDSCs, after $\mathrm{CpG}-\mathrm{ODN}+\mathrm{IFA}$ treatment. Interestingly, in young mice, after reaching a peak on day 10 after treatment, myeloid cell numbers and their regulatory function diminished, returning to normal levels before day 25 . However in aged animals, the myeloid cell population expanded by day 10 after treatment was maintained or even increased at least until day 40 , conserving their suppressor function. This suggests that the inflammatory stimulus of CpG-ODN+IFA may expand MDSCs in spleen of aged mice for a longer period of time than in young mice, and preserve their regulatory function, probably as a way to prevent pathological inflammatory damage. As evidence of inflammatory response we found elevated levels of IL-6 in plasma of aged but not in young mice after CpG-ODN+IFA treatment (data not shown). Studies in aged mice and humans indicate that older adults have elevated levels of pro-inflammatory cytokines, clotting factors and acute phase reactants in the steady state, a phenomenon referred to as 'inflamm-ageing' [11, 32]. Our

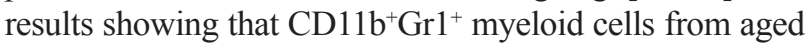
mice are more resistant to spontaneous apoptosis may suggest that the persistent expansion of these cells is due to heir prolonged lifespan. Chornoguz et al. suggest that inflammation protects MDSCs against extrinsic-induced apoptosis, resulting in MDSCs with a longer in vivo half-life [33] and similar results were observed by Ko et al. [34] in tumor-bearing mice.

A recent publication from Shirota et al. showed that intratumoral administration of $\mathrm{CpG}-\mathrm{ODN}$ reduces the immune suppressive activity and number of monocytic MDSCs in a model of CT26 tumor-bearing mice [35]. Their study is based in a model of large, established 


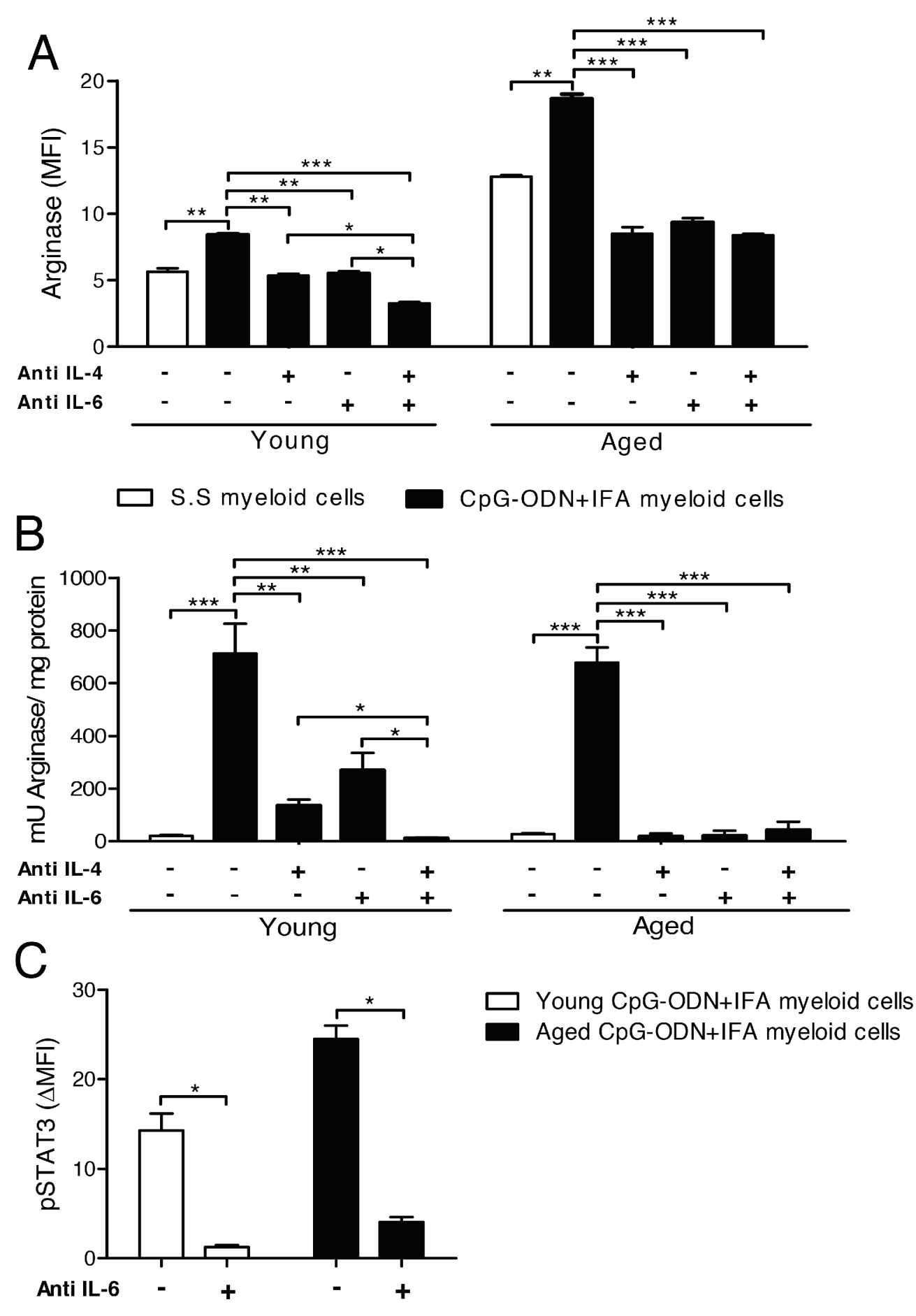

Figure 6: Environmental IL-4 and IL-6 are involved in arginase induction in myeloid cells from CpG-ODN+IFAtreated mice. (A-C) After ten days of S.S or CpG-ODN+IFA-treatment, myeloid cells were isolated from the spleen of young and aged mice and co-cultured with naïve $\mathrm{T}$ cells isolated from young mice stimulated with anti-CD3 plus anti-CD28. Cytokine neutralizing antibodies were added separately or together. (A) After $24 \mathrm{~h}$ of co-culture, cells were collected and stained with anti-CD11b and anti-Gr1 antibodies, fixed, permeabilized and stained for arginase-1. Results represent the expression of arginase-1 on CD11b $\mathrm{Gr}^{+}{ }^{+}$gated cells. (B) After $48 \mathrm{~h}$ of co-culture, cells were lysed and prepared for arginase activity analysis. Results are expressed as $\mathrm{mU}$ of enzyme activity per $\mathrm{mg}$ of protein lysate. (C) Anti-mouse IL6 neutralizing antibody was added and, after $30 \mathrm{~min}$ culture, cells were collected, fixed, permeabilized, and stained with anti-CD11b, anti-Gr1, and anti-pSTAT3. pSTAT3 levels were analyzed on $\mathrm{CD} 11 \mathrm{~b}^{+} \mathrm{Gr} 1^{+}$cells. Results represent the expression of pSTAT3 (MFI) at 30 min by subtracting that measured at zero time $(\triangle \mathrm{MFI})$. (A-C) Data are pooled from two independent experiments (mean \pm SEM; $n=3$ mice/group). ${ }^{*} p<0.05 ;{ }^{* *} p<0.01 ;{ }^{* *} p<0.001$. 
tumors, where the number and immunosuppressive activity of MDSC was enhanced. The route of $\mathrm{CpG}$ ODN administration also critically affects outcome, in that local but not systemic delivery of CpG-ODN altered the tumor microenvironment and was key to reducing the number and suppressive activity of MDSC. Zoglmeier et al. showed that $\mathrm{CpG}-\mathrm{ODN}$ injection in tumor-bearing mice induces the expansion of $\mathrm{CD} 1 \mathrm{~b}^{+} \mathrm{Gr} 1^{+}$cells but does not increase their suppressive function [36]. They administrated $\mathrm{CpG}-\mathrm{ODN}$ alone, whereas in our model CpG-ODN is combined with the slow-release delivery system, IFA, which could be one of the reasons for the differences observed in our study.

Among other factors, the age-related decrease of immune function is explained by an impaired $\mathrm{T}$ cell proliferative response [37-38]. Thus, our results show that splenocytes from aged saline solution-treated mice presented reduced proliferation levels, and, after CpG-ODN+IFA treatment, they showed even lower proliferative response. When myeloid cells isolated from spleen of aged-treated mice were cultured with T-cells from young animals, they suppressed their proliferation. On a per cell basis, myeloid cells from aged treated mice present the same ability to suppress T-cell proliferative response as those from their younger counterparts. The suppression of T-cell proliferative response exerted by splenic MDSCs from aged CpGODN+IFA-treated mice is mediated by arginase activity, as the addition of the arginase inhibitor, nor-NOHA, to the cultures almost completely restored T-cell proliferation. These results correlate with the increased L-arginine uptake in myeloid cells from young CpG-ODN+IFA-treated mice, resulting in the depletion of this amino acid from the cell microenvironment [15]. However, we cannot discard other mechanisms activated in these cells that could, to a lesser extent, also be responsible for the suppression.

Many reports established that factors and signals present in MDSCs microenvironment may induce their activation, up-regulating different suppressor mechanisms. These factors are produced mainly by activated T-cells, tumor stromal cells or induced by different bacterial and viral products $[1,8]$. Several studies have indicated that the signaling pathway downstream of IL-4R $\alpha$ (activated by the binding of either IL-4 or IL-13) and STAT6 plays an important role in MDSC activation [1, 39-40]. In addition, Qualls et al. demonstrated that STAT3activating cytokines IL-6, IL-10, and G-CSF, produced by mycobacteria-infected macrophages, are critical for arginase-1 expression [20]. Similarly, many studies have shown that STAT3 is one of the main transcription factors that regulate the expansion of MDSCs [1, 41-42], but little is known about the role of IL-6 and STAT3 in MDSCs activation. We observed increased phosphorylation levels of STAT3 and STAT6 in young and aged myeloid cells from CpG-ODN+IFA-treated mice. Augmented STAT3 and STAT6 phosphorylation in MDSCs from CpGODN+IFA-treated mice correlated with their increased arginase activity and arginase-1 expression at both ages.
No significant difference was found in IL-4 levels in cultures of myeloid cells isolated from young or aged mice after CpG-ODN+IFA-treatment compared to their saline solution counterparts. However, myeloid cells from CpG-ODN+IFA-treated mice presented augmented STAT6 phosphorylation, correlating with higher expression of CD124 (IL-4R $\alpha$ ), which could be involved in the elevated response of these cells to IL-4 resulting in arginase induction. Similarly, a recent report demonstrated that IL6 , acting on a cell-autonomous level, directly induced the expression of IL-4R $\alpha$, and therefore primed macrophages for IL-4 dependent activation of STAT6 [43]. Interestingly, we found elevated levels of IL-6 in cultures of myeloid cells from CpG-ODN+IFA-treated mice along with augmented STAT3 activation. Our observations that the neutralization of each IL-4 or IL-6 in the culture medium of myeloid cells from aged CpG-ODN+IFA-treated mice lead to a reduction of arginase-1 expression and enzyme activity, indicate that the presence of both cytokines together is required for arginase induction in these cells, whereas in myeloid cells from young treated mice, the presence of IL-4 or IL-6 alone is sufficient to induce arginase- 1 expression and activity. IL-4 and IL- 6 may be synergizing for arginase induction in myeloid cells from young treated mice, as arginase activity was completely reduced when both cytokines were neutralized.

Several cellular signaling pathways involved in eliciting immune responses have also been shown to be defective in different cell types during aging [17, 44-46]. Therefore, the requirement of both IL-4/STAT6 and IL-6/ STAT3 pathways to elicit arginase induction in myeloid cells from aged CpG-ODN+IFA mice, unlike the case of their younger counterparts, might be linked to ageassociated changes in signal transduction functions, although further studies are required to test this hypothesis.

In summary, this work adds more information to the growing evidence suggesting that the expansion of myeloid cells with suppressor function may represent a common response to different forms of inflammation. Aged mice harbor elevated numbers of myeloid cells, possibly in response to their basal inflammatory conditions which after an inflammatory stimulus such as CpGODN+IFA, expand for longer time than in young mice and upregulate their suppressive abilities. These cells might be contributing to the dysregulation of the immune system during aging, to the inability to swiftly combat infection and to an increased susceptibility to chronic disease states and autoimmune conditions.

\section{METHODS}

\section{Synthetic oligodeoxynucleotides}

The synthetic oligodeoxynucleotide used was CpG-ODN 1826; B-class oligodeoxynucleotide (5'-TC CATGACGTTCCTGACGTT-3') synthesized with a nuclease-resistant phosphorothioate backbone and 
containing no LPS contaminants (Operon Technologies., Alameda, CA, USA). CpG-ODN stock solution was prepared in sterile apyrogenic $0.9 \% \mathrm{NaCl}$ saline solution (B. Braun Medical S.A, Mar del Plata, Buenos Aires, Argentina). The endotoxin content in oligodeoxynucleotide after reconstitution $(1 \mathrm{mg} / \mathrm{mL})$, determined by a standard Limulus amebocyte lysate assay (BioWhittaker Inc., Walkersville, MD, USA), was $<1$ endotoxin U/mL.

\section{Laboratory animals and treatments}

Six to 8-week-old (young) female BALB/c mice were provided by the Veterinary School of the National University of La Plata animal production area (La Plata, Argentina). 18-20-month-old (aged) female mice were received as 6to 8 -weeks old and maintained in our animal facility until use according to the terms of the Guide to the Care and Use of Experimental Animals, published by the Canadian Council on Animal Care (with the assurance number A5802-01 assigned by the Office of Laboratory Animal Welfare (NIH)). Our Institutional Experimentation Animal Committee (authorization No. 15-01-44195 and HCD resolution 450/07) also approved the animal handling and experimental procedures. CpG-ODN, at $15.7 \mathrm{nmol} / \mathrm{mouse}$, emulsified in IFA (Sigma-Aldrich, St. Louis, MO), was injected subcutaneously (s.c) into 2 sites of each mouse $(0.2$ $\mathrm{mL} / \mathrm{site}$ ). Control mice received injections of saline solution (S.S) alone. Splenocyte suspensions were obtained 10 days or, when indicated, 25, 40 and 80 days after treatment.

\section{Spleen cells culture}

Spleens were surgically removed and red blood cells were lysed using RBC lysing buffer (SigmaAldrich). After washing, cell suspensions were cultured in GIBCO $^{\circledR}$ RPMI 1640 medium (Life Technologies, Argentina) supplemented with 10\% heat-inactivated fetal bovine serum (PAA Laboratories GmbH, Linz, Austria), $2 \mathrm{mM} \mathrm{GIBCO}^{\circledR}$ Glutamax, $100 \mathrm{U} / \mathrm{mL}$ Penicillin and $100 \mu \mathrm{g} / \mathrm{mL}$ Streptomycin (all from Life Technologies) and $50 \mu \mathrm{M}$ 2-mercaptoethanol (Sigma-Aldrich) in a humidified incubator at $37^{\circ} \mathrm{C}$ and $5 \% \mathrm{CO}_{2}$ for the period of time specified for each experiment.

When indicated, neutralizing antibodies were added at the beginning of the cultures: NA/LE anti-mouse IL4 (11B11) at a final concentration of $1 \mu \mathrm{g} / \mathrm{mL}, \mathrm{NA} / \mathrm{LE}$ antimouse IL6 (MP5-20F3) $1 \mu \mathrm{g} / \mathrm{mL}, \mathrm{NA} / \mathrm{LE}$ anti-mouse IL10 (JES5-2A5) $1 \mu \mathrm{g} / \mathrm{mL}$, and anti-mouse isotype-matched control antibodies were obtained from Becton Dickinson Argentina or eBioscience (San Diego, CA, USA). Cytokine neutralization was controlled by measurement of their respective levels by ELISA in culture supernatants.

\section{Flow cytometry analysis}

Cells were pre-incubated with anti-CD16/32 (2.4G2) for $15 \mathrm{~min}$ at $4^{\circ} \mathrm{C}$, and then stained with fluorochrome-labeled antibodies for $30 \mathrm{~min}$ at $4^{\circ} \mathrm{C}$. Cells were washed twice and 7 -AAD was then added to exclude dead cells. The antibodies used against mouse CD11b (M1/70), Gr1 (RB6-8C5), Ly6G (1A8), Ly6C (AL-21), CD31 (390), CD124 (mIL4R-M1), CD86 (GL1), MHC class II (2G9), CD274 (PD-L1, clone MIH5), CD273 (PD-L2, clone TY25) were purchased from Becton Dickinson Argentina. For intracellular staining of arginase-1, cells were first stained with fluorochromelabeled antibodies against mouse CD11b and Gr1. Then cells were permeabilized with BD Cytofix/Cytoperm ${ }^{\text {TM }}$ Plus kit (Becton Dickinson Argentina), following the manufacturer's protocols, before being incubated for intracellular arginase-1 (8C9) (Santa Cruz Biotechnology, Santa Cruz, CA, USA) or isotype-matched control antibody (Becton Dickinson Argentina).

For the apoptosis assay, mitochondrial depolarization was measured using $50 \mathrm{nM}$ tetramethylrhodamine ethyl ester (TMRE; Invitrogen) [47]. Cells were stained with fluorochrome-labeled antibodies against mouse $\mathrm{CD} 11 \mathrm{~b}$ and $\mathrm{Gr} 1$ for $30 \mathrm{~min}$ at $4^{\circ} \mathrm{C}$ and then incubated with TMRE for $30 \mathrm{~min}$ at $37^{\circ} \mathrm{C}$. Cells incubated with $100 \mu \mathrm{M}$ FCCP (carbonyl cyanide 4-(trifluoromethoxy) phenylhydrazone) were used as positive controls. Data acquisition was performed on a FACS Canto II cytometer (BD Biosciences) and analyzed using FlowJo software (Tree Star Inc., Ashland, OR).

\section{Arginase activity assay}

Cells were lysed with $0.1 \%$ Tritón X-100 (SigmaAldrich) plus protease inhibitors (Sigma-Aldrich) for 30 min. Arginase activity was measured in cell lysates by colorimetric assay for the detection of urea, as described by Corraliza et al. [48] with slight modifications [31]. One unit of enzyme activity was defined as the amount of enzyme that catalyzed the formation of $1 \mu \mathrm{mol}$ of urea/min.

\section{Cytokine detection assay}

Concentrations of different cytokines were measured by standard sandwich ELISA following instructions from the manufacturer and standardized with recombinant murine cytokines. The antibody pairs used were as follows (listed by capture/biotinylated detection): IL-6, MP520F3/MP5-32C11; IL-4, 11B11/BVD6-24G2; IL-10, JES5-2A5/JES5-16E3. All antibodies were obtained from Becton Dickinson Argentina or eBioscience (San Diego, CA, USA). The concentrations were expressed in relation to standard curves constructed by assaying serial dilutions of the respective murine standard cytokine.

\section{Cell isolation}

A single-cell suspension was prepared from the spleen of mice and washed in MACS buffer. CD11b cells were isolated using corresponding MACS magnetic 
microbeads (Miltenyi Biotec, Auburn, CA), and the purity of $\mathrm{CD} 11 \mathrm{~b}^{+} \mathrm{Gr}^{+}$cells was routinely $>95 \%$ as assessed by flow cytometry.

To purify T-cells, splenocytes from wild-type 6-8 week-old female mice were stained with APC-CD90.2 (53-2.1; Becton Dickinson Argentina) and isolated using cell sorting on a FACSAria II cell sorter (BD Biosciences). Purity was routinely $>98 \%$.

\section{T-cell stimulation and in vitro suppression assays}

For mitogenic-induced cell proliferation, splenocytes $\left(2 \times 10^{6} \mathrm{cell} / \mathrm{mL}\right)$ were cultured for $72 \mathrm{~h}$ in round-bottomed 96-well plates in the presence or absence of ConA (5 $\mu \mathrm{g} / \mathrm{mL})$ (Sigma-Aldrich). $1 \mu \mathrm{Ci}$ [3H]-thymidine (Dupont NEN, Boston, MA, USA) was added to each well and, $18 \mathrm{~h}$ later, plates were harvested and then processed for measurement of incorporated radioactivity.

For proliferation measurement in co-cultures, $\mathrm{CD} 11 \mathrm{~b}^{+}$cells were cultured in supplemented medium in triplicate in round-bottomed 96-well plates at $1 \times$ $10^{6} / \mathrm{mL}$. In parallel, $1 \times 10^{6} / \mathrm{mL}$ splenic purified CD90 $0^{+}$ T-cells from normal mice were stimulated with anti-CD3 $(1 \mathrm{mg} / \mathrm{mL})$ plus anti-CD28 (1 mg/mL) for $24 \mathrm{~h}$. The stimulated T-cells were then cultured with the CD11 $\mathrm{b}^{+}$ cells (at a 1:1 ratio) for an additional $48 \mathrm{~h}$. To block arginase, $40 \mu \mathrm{M}$ nor-NOHA inhibitor ( $\mathrm{N}^{\mathrm{W}}$-hydroxyl-norL-arginine) (Calbiochem, San Diego, CA, USA) was added at the beginning of culture. T-cell proliferation was tested by $[3 \mathrm{H}]$-thymidine incorporation in a liquid scintillation counter.

\section{Intracellular staining for STAT phosphorylation}

After 30, 90, or $240 \mathrm{~min}$ of co-culture, cells were stained for pSTAT3 and pSTAT6 according to manufacturer's instructions (Becton Dickinson Argentina). Cells were first fixed with $2 \%$ paraformaldehyde for $10 \mathrm{~min}$ at $37^{\circ} \mathrm{C}$ and permeabilized with $90 \%$ ice-cold methanol for $30 \mathrm{~min}$ at $4^{\circ} \mathrm{C}$. The cells were washed and stained with anti-Stat6 (pY641) or anti-Stat3 (pY705) antibodies (Becton Dickinson Argentina) for 30 minutes. Stimulated myeloid cells with IL-6 (100 ng/mL), or with IL-4 (10 ng/ $\mathrm{mL}$ ) were used as positive controls. Data acquisition was performed on a FACS Canto II Cytometer.

\section{Statistical analysis}

Results are expressed as the mean \pm SEM. Data were analyzed using GraphPad Prism software (GraphPad Software, San Diego, CA). Data analysis included the unpaired Student $t$ test, one-way ANOVA and two-way ANOVA followed by a Bonferroni's post test. All data were considered statistically significant for $p$ values $<0.05$.

\section{ACKNOWLEDGMENTS}

M.C.P-P and G.M are Research Career Investigator from CONICET. M.F.H, R.P.R, C.V.G, M.F.S.V, M.I.C and S.D.C thank CONICET for the fellowships granted. We thank Drs. P. Abadie and P. Crespo for valuable technical assistance, and F. Navarro and L. Navarro for excellent animal facility management. We appreciate A. Romero for her help. We thank native speaker Joss Heywood, who revised the manuscript.

This work was supported by grants from Consejo Nacional de Investigaciones Científica y Técnicas (PIP\#11220120100420), Agencia Nacional de Promoción Científica y Técnica (PICT 2013 \#0019), and Secretaría de Ciencia y Tecnología de la Universidad Nacional de Córdoba.

\section{CONFLICTS OF INTEREST}

The authors declare no commercial or financial conflict of interest.

\section{REFERENCES}

1. Gabrilovich DI, Nagaraj S. Myeloid-derived suppressor cells as regulators of the immune system. Nat Rev Immunol. 2009; 9:162-174.

2. Gabrilovich DI, Ostrand-Rosenberg S, Bronte V. Coordinated regulation of myeloid cells by tumours. Nat Rev Immunol. 2012; 12:253-268.

3. Almand B, Clark JI, Nikitina E, van Beynen J, English NR, Knight SC, Carbone DP, Gabrilovich DI. Increased production of immature myeloid cells in cancer patients: a mechanism of immunosuppression in cancer. J Immunol. 2001; 166:678-689.

4. Delano MJ, Scumpia PO, Weinstein JS, Coco D, Nagaraj S, Kelly-Scumpia KM, O’Malley KA, Wynn JL, Antonenko S, Al-Quran SZ, Swan R, Chung CS, Atkinson MA, et al. MyD88-dependent expansion of an immature GR-1(+) $\mathrm{CD} 11 \mathrm{~b}(+)$ population induces $\mathrm{T}$ cell suppression and Th2 polarization in sepsis. J Exp Med. 2007; 204:1463-1474.

5. Bronte V, Wang M, Overwijk WW, Surman DR, Pericle F, Rosenberg SA, Restifo NP. Apoptotic death of CD8+ T lymphocytes after immunization: induction of a suppressive population of Mac-1+/Gr-1+ cells. J Immunol. 1998; 161:5313-5320.

6. Movahedi K, Guilliams M, Van den Bossche J, Van den Bergh R, Gysemans C, Beschin A, De Baetselier P, Van Ginderachter JA. Identification of discrete tumorinduced myeloid-derived suppressor cell subpopulations with distinct $\mathrm{T}$ cell-suppressive activity. Blood. 2008; 111:4233-4244.

7. Ostrand-Rosenberg S, Sinha P. Myeloid-derived suppressor cells: linking inflammation and cancer. J Immunol. 2009; 182:4499-4506. 
8. Condamine T, Gabrilovich DI. Molecular mechanisms regulating myeloid-derived suppressor cell differentiation and function. Trends Immunol. 2011; 32:19-25.

9. Liscovsky MV, Ranocchia RP, Alignani DO, Gorlino CV, Moron G, Maletto BA, Pistoresi-Palencia MC. CpGODN+IFN-gamma confer pro- and anti-inflammatory properties to peritoneal macrophages in aged mice. Exp Gerontol. 2011; 46:462-467.

10. Beerman I, Maloney WJ, Weissmann IL, Rossi DJ. Stem cells and the aging hematopoietic system. Curr Opin Immunol. 2010; 22:500-506.

11. Shaw AC, Goldstein DR, Montgomery RR. Age-dependent dysregulation of innate immunity. Nat Rev Immunol. 2013; 13:875-887.

12. Alignani D, Maletto B, Liscovsky M, Ropolo A, Moron G, Pistoresi-Palencia MC. Orally administered OVA/CpG-ODN induces specific mucosal and systemic immune response in young and aged mice. J Leukoc Biol. 2005; 77:898-905.

13. Maletto BA, Ropolo AS, Liscovsky MV, Alignani DO, Glocker M, Pistoresi-Palencia MC. CpG oligodeoxinucleotides functions as an effective adjuvant in aged BALB/c mice. Clin Immunol. 2005; 117:251-261.

14. Maletto B, Ropolo A, Moron V, Pistoresi-Palencia MC. CpG-DNA stimulates cellular and humoral immunity and promotes Th1 differentiation in aged $\mathrm{BALB} / \mathrm{c}$ mice. J Leukoc Biol. 2002; 72:447-454.

15. Ranocchia RP, Gorlino CV, Crespo MI, Harman MF, Liscovsky MV, Moron G, Maletto BA, PistoresiPalencia MC. Arginase-dependent suppression by CpGODN plus IFA-induced splenic myeloid CD11b(+)Gr1(+) cells. Immunol Cell Biol. 2012; 90:710-721.

16. Pang WW, Price EA, Sahoo D, Beerman I, Maloney WJ, Rossi DJ, Schrier SL, Weissman IL. Human bone marrow hematopoietic stem cells are increased in frequency and myeloid-biased with age. Proc Natl Acad Sci U S A. 2011; 108:20012-20017.

17. Enioutina EY, Bareyan D, Daynes RA. A role for immature myeloid cells in immune senescence. J Immunol. 2011; 186:697-707.

18. Jackaman C, Radley-Crabb HG, Soffe Z, Shavlakadze T, Grounds MD, Nelson DJ. Targeting macrophages rescues age-related immune deficiencies in $\mathrm{C} 57 \mathrm{BL} / 6 \mathrm{~J}$ geriatric mice. Aging Cell. 2013; 12:345-357.

19. Youn JI, Nagaraj S, Collazo M, Gabrilovich DI. Subsets of myeloid-derived suppressor cells in tumor-bearing mice. J Immunol. 2008; 181:5791-5802.

20. Qualls JE, Neale G, Smith AM, Koo MS, DeFreitas AA, Zhang H, Kaplan G, Watowich SS, Murray PJ. Arginine usage in mycobacteria-infected macrophages depends on autocrine-paracrine cytokine signaling. Sci Signal. 2010; 3:ra62.

21. Narita Y, Kitamura H, Wakita D, Sumida K, Masuko K, Terada S, Nakano K, Nishimura T. The key role of IL-6arginase cascade for inducing dendritic cell-dependent
CD4(+) $\mathrm{T}$ cell dysfunction in tumor-bearing mice. J Immunol. 2013; 190:812-820.

22. Vasquez-Dunddel D, Pan F, Zeng Q, Gorbounov M, Albesiano E, Fu J, Blosser RL, Tam AJ, Bruno T, Zhang H, Pardoll D, Kim Y. STAT3 regulates arginase-I in myeloidderived suppressor cells from cancer patients. J Clin Invest. 2013; 123:1580-1589.

23. Rossi DJ, Bryder D, Zahn JM, Ahlenius H, Sonu R, Wagers AJ, Weissman IL. Cell intrinsic alterations underlie hematopoietic stem cell aging. Proc Natl Acad Sci U S A. 2005; 102:9194-9199.

24. Woolthuis CM, de Haan G, Huls G. Aging of hematopoietic stem cells: Intrinsic changes or micro-environmental effects? Curr Opin Immunol. 2011; 23:512-517.

25. Sen G, Chen Q, Snapper CM. Immunization of aged mice with a pneumococcal conjugate vaccine combined with an unmethylated $\mathrm{CpG}$-containing oligodeoxynucleotide restores defective immunoglobulin $\mathrm{G}$ antipolysaccharide responses and specific CD4+-T-cell priming to young adult levels. Infect Immun. 2006; 74:2177-2186.

26. Wingender G, Garbi N, Schumak B, Jungerkes F, Endl E, von Bubnoff D, Steitz J, Striegler J, Moldenhauer G, Tuting T, Heit A, Huster KM, Takikawa O, et al. Systemic application of CpG-rich DNA suppresses adaptive T cell immunity via induction of IDO. Eur J Immunol. 2006; 36:12-20.

27. Morecki S, Gelfand Y, Yacovlev E, Eizik O, Shabat Y, Slavin S. CpG-induced myeloid CD11b+Gr-1+ cells efficiently suppress $\mathrm{T}$ cell-mediated immunoreactivity and graft-versus-host disease in a murine model of allogeneic cell therapy. Biol Blood Marrow Transplant. 2008; 14:973-984.

28. Mellor AL, Baban B, Chandler PR, Manlapat A, Kahler DJ, Munn DH. Cutting edge: CpG oligonucleotides induce splenic CD19+ dendritic cells to acquire potent indoleamine 2, 3-dioxygenase-dependent $\mathrm{T}$ cell regulatory functions via IFN Type 1 signaling. J Immunol. 2005; 175:5601-5605.

29. Schwartz DA, Wohlford-Lenane CL, Quinn TJ, Krieg AM. Bacterial DNA or oligonucleotides containing unmethylated $\mathrm{CpG}$ motifs can minimize lipopolysaccharide-induced inflammation in the lower respiratory tract through an IL-12-dependent pathway. J Immunol. 1999; 163:224-231.

30. Samarasinghe R, Tailor P, Tamura T, Kaisho T, Akira S, Ozato K. Induction of an anti-inflammatory cytokine, IL-10, in dendritic cells after toll-like receptor signaling. J Interferon Cytokine Res. 2006; 26:893-900.

31. Liscovsky MV, Ranocchia RP, Gorlino CV, Alignani DO, Moron G, Maletto BA, Pistoresi-Palencia MC. Interferongamma priming is involved in the activation of arginase by oligodeoxinucleotides containing $\mathrm{CpG}$ motifs in murine macrophages. Immunology. 2009; 128:e159-169.

32. Fagiolo U, Cossarizza A, Scala E, Fanales-Belasio E, Ortolani C, Cozzi E, Monti D, Franceschi C, Paganelli R. Increased cytokine production in mononuclear cells of healthy elderly people. Eur J Immunol. 1993; 23:2375-2378. 
33. Chornoguz O, Grmai L, Sinha P, Artemenko KA, Zubarev RA, Ostrand-Rosenberg S. Proteomic pathway analysis reveals inflammation increases myeloidderived suppressor cell resistance to apoptosis. Mol Cell Proteomics. 2011; 10:M110. 002980.

34. Ko JS, Rayman P, Ireland J, Swaidani S, Li G, Bunting KD, Rini B, Finke JH, Cohen PA. Direct and differential suppression of myeloid-derived suppressor cell subsets by sunitinib is compartmentally constrained. Cancer Res. 2010; 70:3526-3536.

35. Shirota Y, Shirota H, Klinman DM. Intratumoral injection of $\mathrm{CpG}$ oligonucleotides induces the differentiation and reduces the immunosuppressive activity of myeloid-derived suppressor cells. J Immunol. 2012; 188:1592-1599.

36. Zoglmeier C, Bauer H, Norenberg D, Wedekind G, Bittner P, Sandholzer N, Rapp M, Anz D, Endres S, Bourquin C. CpG blocks immunosuppression by myeloidderived suppressor cells in tumor-bearing mice. Clin Cancer Res. 2011; 17:1765-1775.

37. Haynes L, Linton PJ, Eaton SM, Tonkonogy SL, Swain SL. Interleukin 2, but not other common gamma chain-binding cytokines, can reverse the defect in generation of CD4 effector T cells from naive T cells of aged mice. J Exp Med. 1999; 190:1013-1024.

38. Haynes L, Eaton SM, Burns EM, Rincon M, Swain SL. Inflammatory cytokines overcome age-related defects in CD4 $\mathrm{T}$ cell responses in vivo. J Immunol. 2004; 172:5194-5199.

39. Bronte V, Serafini P, De Santo C, Marigo I, Tosello V, Mazzoni A, Segal DM, Staib C, Lowel M, Sutter G, Colombo MP, Zanovello P. IL-4-induced arginase 1 suppresses alloreactive $\mathrm{T}$ cells in tumor-bearing mice. J Immunol. 2003; 170:270-278.

40. Rutschman R, Lang R, Hesse M, Ihle JN, Wynn TA, Murray PJ. Cutting edge: Stat6-dependent substrate depletion regulates nitric oxide production. J Immunol. 2001; 166:2173-2177.
41. Sumida K, Wakita D, Narita Y, Masuko K, Terada S, Watanabe K, Satoh T, Kitamura H, Nishimura T. Anti-IL-6 receptor $\mathrm{mAb}$ eliminates myeloid-derived suppressor cells and inhibits tumor growth by enhancing T-cell responses. Eur J Immunol. 2012; 42:2060-2072.

42. Wu L, Du H, Li Y, Qu P, Yan C. Signal transducer and activator of transcription 3 (Stat3C) promotes myeloid-derived suppressor cell expansion and immune suppression during lung tumorigenesis. Am J Pathol. 2011; 179:2131-2141.

43. Mauer J, Chaurasia B, Goldau J, Vogt MC, Ruud J, Nguyen KD, Theurich S, Hausen AC, Schmitz J, Bronneke HS, Estevez E, Allen TL, Mesaros A, et al. Signaling by IL-6 promotes alternative activation of macrophages to limit endotoxemia and obesity-associated resistance to insulin. Nat Immunol. 2014; 15:423-430.

44. Chelvarajan RL, Liu Y, Popa D, Getchell ML, Getchell TV, Stromberg AJ, Bondada S. Molecular basis of age-associated cytokine dysregulation in LPS-stimulated macrophages. J Leukoc Biol. 2006; 79:1314-1327.

45. Sun L, Hurez VJ, Thibodeaux SR, Kious MJ, Liu A, Lin P, Murthy K, Pandeswara S, Shin T, Curiel TJ. Aged regulatory $\mathrm{T}$ cells protect from autoimmune inflammation despite reduced STAT3 activation and decreased constraint of IL-17 producing T cells. Aging Cell. 2012; 11:509-519.

46. McKay BR, Ogborn DI, Baker JM, Toth KG, Tarnopolsky MA, Parise G. Elevated SOCS3 and altered IL-6 signaling is associated with age-related human muscle stem cell dysfunction. Am J Physiol Cell Physiol. 2013; 304:C717-728.

47. Reddy PV, Rao KV, Norenberg MD. The mitochondrial permeability transition, and oxidative and nitrosative stress in the mechanism of copper toxicity in cultured neurons and astrocytes. Lab Invest. 2008; 88:816-830.

48. Corraliza IM, Campo ML, Soler G, Modolell M. Determination of arginase activity in macrophages: a micromethod. J Immunol Methods. 1994; 174:231-235. 